ORIGINAL ARTICLE

\title{
Biological monitoring of occupational exposure to $\mathrm{N}, \mathrm{N}$-dimethylacetamide with identification of a new metabolite
}

\author{
L Perbellini, A Princivalle, M Caivano, R Montagnani
}

Occup Environ Med 2003;60:746-751

See end of article for authors' affiliations

....................

Correspondence to: Prof. L Perbellini, Service of Occupational Medicine, Policlinico GB Rossi, 37134 Verona, Italy; perbelui@mail.univr.it

Accepted

17 December 2002

\begin{abstract}
Aims: To study the concentration of $\mathrm{N}, \mathrm{N}$-dimethylacetamide (DMA) and its metabolite, $\mathrm{N}$-methylacetamide (NMA), in urine of workers occupationally exposed to DMA in a factory producing synthetic acrylic fibres.

Methods: During the first phase, 223 workers exposed to low environmental concentrations of DMA provided urine samples at the end of a work shift. High concentrations of the unmodified solvent and its metabolite were found in a group of workers whose job was to start up machinery. The second and third phases focused on conditions favouring high uptake of DMA.

Results: The highest concentrations of unmodified solvent and NMA were found in the urine of workers recently engaged in starting up machinery. NMA in urine was $1.5-173.6 \mathrm{mg} / \mathrm{g}$ creatinine (median 20.5). In spite of the low environmental concentration, about $20 \%$ of the urine concentration of NMA was higher than $30 \mathrm{mg} / \mathrm{g}$ creatinine. Dermal absorption of DMA was high. A shower and a change of clothing at the end of the work shift, and washing away any solvent left on the skin, ensured that dermal absorption of DMA did not continue. This significantly reduced the NMA urinary concentration at values lower than $30 \mathrm{mg} / \mathrm{g}$ creatinine. In some urine samples, S-acetamidomethyl-mercapturic acid was identified by NMR analysis; this is probably a metabolite of N,N-dimethylacetamide-it has never before been identified in humans or animals.

Conclusions: Even at low environmental concentrations of DMA, dermal absorption can be considerable. Unmodified DMA and NMA concentrations in urine are good biomarkers for monitoring occupational exposure to the solvent.
\end{abstract}

$\mathrm{N}$ ,N-dimethylacetamide (DMA) is a powerful industrial solvent, used in manufacture of synthetic fibres (for example, polyacrylates), some resins and plastics, as well as film and coating formulations. ${ }^{1}$

Its toxicity has been well studied in animals. Excitation, lethargy, weakness, paralysis of the hind paws, epistaxis, convulsions, and coma were found in mice exposed to sublethal doses of the solvent. ${ }^{1}$ Rats and mice treated chronically with relatively low doses of DMA showed the following pathological signs: decrease in body weight, retinal atrophy, variable electroencephalographic changes, and lung, stomach, liver, and kidney lesions. ${ }^{2-4}$

In humans, chronic exposure to DMA causes liver damage (hepatomegaly and altered liver function parameters), headache, hand tremor, and hypertension. ${ }^{5}$ Following exposure to DMA $>300 \mathrm{mg} / \mathrm{kg}$, an abnormal mental state has been observed. ${ }^{4}$

Because of its chemical and physical properties, DMA is readily absorbed by inhalation. ${ }^{6}$ Considerable dermal absorption of fluid DMA has also been observed in experimental studies on animals. ${ }^{4}$ In humans, DMA vapour is also well absorbed by the $\operatorname{skin}^{67}$; this solvent is marked with skin notation by $\mathrm{ACGIH}^{8}$ and DFG. ${ }^{9}$

Biotrasformation of DMA in humans gives rise to acetamide and N-methylacetamide, detected in urine of workers exposed to this solvent. ${ }^{10} \mathrm{~N}$-methylacetamide (NMA) is a good marker for biological monitoring in professional exposure to DMA. ${ }^{11-13}$ Both the ACGIH $^{8}$ and $\mathrm{DFG}^{9}$ recommend $30 \mathrm{mg} / \mathrm{g}$ creatinine of NMA in urine as a biological exposure index. However, kinetic data for this metabolite are limited and contradictory. Borm and colleagues $^{12}$ reported a 16 hour half life for NMA in urine (SD 2), implying its accumulation in the tissues of workers exposed throughout a working week. On the other hand, an experimental human study by Nomiyama and colleagues $^{6}$ calculated the biological half life for urinary NMA as 5.6 hours (SD 1.3), showing no tendency to accumulate.

In this study we report results of biological monitoring of workers exposed to DMA in a factory producing acrylic fibres. The study has been subdivided into three stages. During the first, the concentration of NMA in urine samples obtained from 223 workers showed considerable absorption of DMA in those involved in starting up machinery. In the second and third stages, only workers who had this specific function were tested. Dermal absorption of DMA was unexpectedly high, although considerably reduced by a shower and a change of clothing at the end of the work shift. In some urine samples from workers with high levels of exposure to the solvent, S-acetamidomethylmercapturic acid was identified. This must be considered a new metabolite of DMA in humans.

\section{MATERIALS AND METHODS}

\section{Study design}

The first of the study's three stages involved 223 workers from a chemical industry producing synthetic acrylic fibres. The production process starts in the polymerisation department,

\footnotetext{
Abbreviations: $A C G I H$, American Conference of Governmental Industrial Hygienists; DFG, Deutsche Forschungsgemeinschaft; DMA, $\mathrm{N}, \mathrm{N}$-dimethylacetamide; NMA, N-methylacetamide
} 
where acrylic resin is prepared. This is blended with DMA to form a thick mix, which is then spun through about 600 small holes over an area of $100 \mathrm{~cm}^{2}$ to produce acrylic fibres. These are coagulated in a hot water solution of DMA (about $50 \%$, at $50^{\circ} \mathrm{C}$ ), after which the fibres are removed from the solution, stretched, washed, vaporised, dried, and packed. The plant concerned had 22 machines for preparing fibres, all in one large room. The task of most workers was to check the automatic production of fibres. Every day, two groups of six workers started up two or three spinning machines (an operation taking about 30 minutes), which would then work continuously for about 15 days except for occasional unscheduled stoppages. All workers were cyclically involved in these duties.

Recurring measurements of environmental DMA constantly showed low levels in air (median not exceeding $1.5 \mathrm{ppm}$ ). Biological monitoring of exposure to DMA was carried out, to confirm the low environmental pollution of this solvent. The 223 workers all provided a urine sample at the end of their work shifts, irrespective of their specific function during the work shift. Some urine samples thus came from workers recently engaged in starting up of spinning machines, while most samples came from those who had performed this duty on previous days.

In the urine samples, unchanged DMA and NMA were measured. Forty three workers (about 19\%) had urinary NMA levels higher than $30 \mathrm{mg} / \mathrm{g}$ creatinine.

After this observation, a group of 36 workers (six teams of six workers), specifically trained and responsible only for staring up of machinery, was identified by the management of the factory.

The second stage of the study focused on this group, multiple urine samples being obtained from 35 of 36 workers. To identify when most DMA was absorbed, each worker provided three urine samples: before starting the shift, nearly halfway through the shift (after starting up the machines), and at the end of the shift. During machine start up operations, which took about 30 minutes, some workers had to immerse their hands (protected by gloves) in a water/ DMA solution $(50 \%)$ at a temperature of $50^{\circ} \mathrm{C}$ (we recorded these workers). Seventeen workers (belonging to the 2nd, 4th, and 6th teams) were supplied with an active charcoal mask. Workers in the 1st, 3rd, and 5th teams did not use a mask. One aim of the study was to assess the efficacy of this device. Personal breathing zone samples from some workers were collected extemporaneously.

The environmental and biological results of this second stage of the study confirmed that DMA levels in the air were low. For very short periods (less than five minutes), they sometimes reached 5-10 ppm-not sufficient to account for the high urinary NMA.

The third phase of the study involved the group of 36 workers to ascertain whether an end of shift shower and change of clothing would reduce DMA absorption (clothes used during work were light and quickly became damp, because of high humidity and temperature). The workers involved in this part of the study rotated their shifts as follows: two days rest, two days on the morning shift (6 am to $2 \mathrm{pm})$, two days on the afternoon shift $(2-10 \mathrm{pm})$, and two days on the night shift. Each worker was required to provided five urine samples on three successive days, as follows:

- Before the first shift, after two days rest

- At the end of the shift

- At the beginning of the following shift (16 hours later)

- At the end of this shift

- At the beginning of the third shift (24 hours later).
Twenty five workers agreed to take part in this phase. Satisfactory data were obtained for 17 workers, who gave at least four of the five required urine samples.

\section{Urine samples}

All urine samples were placed in glass tubes with a capacity of about $150 \mathrm{ml}$, closed with screw caps. We preferred glass to the plastic commonly used for urine sample containers, to ensure that they absorbed no DMA. Biological samples were maintained at $4^{\circ} \mathrm{C}$ until analysis for NMA and DMA, performed within seven days of collection. A portion of urine was stored and maintained at $-20^{\circ} \mathrm{C}$, to test for any other metabolites.

The urinary concentrations of N-methylacetamide were given in relation to creatinine excretion, as suggested by ACGIH, ${ }^{8}$ to provide some correction for fluctuation of urine output. Urine samples with creatinine $<0.5 \mathrm{~g} / \mathrm{l}$ or $>3.5 \mathrm{~g} / \mathrm{l}$ were not included in the analysis. Since unmodified N,Ndimethylacetamide in urine is excreted by diffusion, like most other industrial solvents, ${ }^{14}$ adjustment for solute is inappropriate; measurements were made in $\mathrm{mg} / \mathrm{l}$.

\section{Analysis of $\mathrm{N}, \mathrm{N}$-dimethylacetamide and $\mathrm{N}$-methylacetamide}

The analysis for DMA and NMA was performed after treatment of $1 \mathrm{ml}$ of urine with $1 \mathrm{ml}$ of methanol, containing $\mathrm{N}$-methylformamide $(100 \mathrm{mg} / \mathrm{l})$ as the internal standard. The mixture was shaken by Wortex for 10 seconds and then left at ambient temperature for 30 minutes, while a little precipitate was forming. A $1 \mu \mathrm{l}$ aliquot of supernatant was drawn for GC/MS analysis. A few samples were also examined for acetamide, as indicated below.

\section{Chemicals}

$\mathrm{N}, \mathrm{N}$-dimethylacetamide, N-methylformamide, acetamide, Nmethylacetamide, and methanol (quoted purity $>99 \%$ ) were obtained from C Erba (Milan). S-acetamidomethylmercapturic acid was synthesised as suggested by Threadgill and Gledhill, ${ }^{15}$ starting from S-acetamidomethyl-L-cysteine, provided by Fluka Chemie AG.

\section{Instruments}

An HP 5890 gas chromatograph, with a $30 \mathrm{~m}$ HP-WAX column (ID $0.2 \mathrm{~mm}$, film thickness $0.25 \mu \mathrm{m}$ ), and an HP HP5970 mass spectrometry detector, were used. Recorded ions were $\mathrm{m} / \mathrm{z} 72$ and 87 for DMA, m/z 73 and 58 for NMA, and $\mathrm{m} / \mathrm{z} 59$ and 44 for $\mathrm{N}$-methylformamide (internal standard). The injector port (split $1 / 10$ ) and detector were kept at $250^{\circ} \mathrm{C}$. The initial oven temperature was $90^{\circ} \mathrm{C}$ for one minute, after which it was brought to $165^{\circ} \mathrm{C}$ at a rate of $10^{\circ} \mathrm{C} / \mathrm{min}$ and kept at that temperature for one minute. The retention time of DMA was about four minutes, while that of NMA and N-methylformamide was close to six minutes. Helium was used as the carrier gas. The detection limit of NMA in urine was $1.5 \mathrm{mg} / \mathrm{l}$; the accuracy and repeatability at $10 \mathrm{mg} / \mathrm{l}$ were $97.8 \%$ and $7.6 \%$ respectively. The detection limit of DMA in urine was $0.05 \mathrm{mg} / \mathrm{l}$; accuracy and repeatability at $1 \mathrm{mg} / \mathrm{l}$ were $108 \%$ and $10.1 \%$ respectively.

By examining the chromatography retention time and the ratio between the two molecular ions registered for each molecule, we identified and measured DMA and NMA in urine.

Some urine samples were treated as suggested by Ghittori and colleagues, ${ }^{16}$ to measure $\mathrm{N}$-acethyl-S-(N-methylcarbamoyl)-cysteine, the mercapturic acid formed from $\mathrm{N}, \mathrm{N}$ dimethylformamide. HPLC allowed us to separate a chromatographic peak, which was analysed by HPLC with a mass detector and by NMR. 
Table 1 Descriptive data of workers involved in our study

\begin{tabular}{|c|c|c|c|c|c|c|c|c|c|c|c|}
\hline \multirow[b]{2}{*}{ Phase } & \multirow[b]{2}{*}{ No. } & \multirow[b]{2}{*}{ Age* $^{*}$} & \multirow[b]{2}{*}{ Length of service ${ }^{*}$} & \multicolumn{4}{|c|}{ Smokingt } & \multicolumn{4}{|c|}{ Alcohol intakeł } \\
\hline & & & & 0 & $<10$ & $10-20$ & $>20$ & 0 & $<50$ & $50-100$ & $>100$ \\
\hline lst & 223 & 40.9 (11.7) & $11.8(10)$ & 65.7 & 14.6 & 16.8 & 2.8 & 48.6 & 42.4 & 8.4 & 0.6 \\
\hline 2nd & 35 & $35.8(10.4)$ & $8.9(10.4)$ & 60 & 20 & 14.3 & 5.7 & 54.3 & 31.4 & 14.3 & - \\
\hline $3 r d$ & 17 & $35.1(10.2)$ & 7.9 (10.1) & 58.8 & 23.5 & 5.9 & 11.8 & 58.8 & 29.4 & 11.8 & - \\
\hline
\end{tabular}

\section{Statistical analysis}

Statistical analysis was performed using Statgraphics software (Statistical Graphics System, ST-SC Inc.). As urinary concentrations of DMA and NMA were not normally distributed, most of the statistical analyses were carried out using non-parametric tests-the Mann-Whitney Wilcoxon (W) test, Kruskal-Wallis and Friedman tests, and Spearman rank correlation coefficient. Sometimes the linear regression was studied after logarithmic transformation of data. A difference was considered statistically significant when $\mathrm{p}$ was lower than 0.05 .

\section{RESULTS}

Table I summarises some descriptive data for the three groups of workers involved in the three phases of the study ( see study design): number, age, length of service, and smoking and drinking habits. We could find no correlation between these parameters and the urinary concentration of DMA and NMA.

\section{$\mathrm{N}, \mathrm{N}$-dimethylacetamide and $\mathrm{N}$-methylacetamide analysis}

Table 2 shows the main statistical parameters for concentration of unmodified urinary DMA and NMA in the first phase of the study. A significant correlation was found between the solvent and its metabolite (Spearman's $r=0.6965$, $\mathrm{p}<0.001)$. Figure 1 shows this correlation as a regression

Table 2 Main statistical parameters for urinary NMA (mg/g creat.) and DMA (mg/l), from workers exposed to the solvent (first phase of study)

\begin{tabular}{lll}
\hline Statistical parameters & NMA (mg/g creat.) & DMA (mg/l) \\
\hline Count & 223 & 223 \\
Average & 20.5 & 0.61 \\
Median & 7.7 & 0.45 \\
Minimum & 1.5 & 0.05 \\
Maximum & 173.6 & 3.15 \\
\hline
\end{tabular}

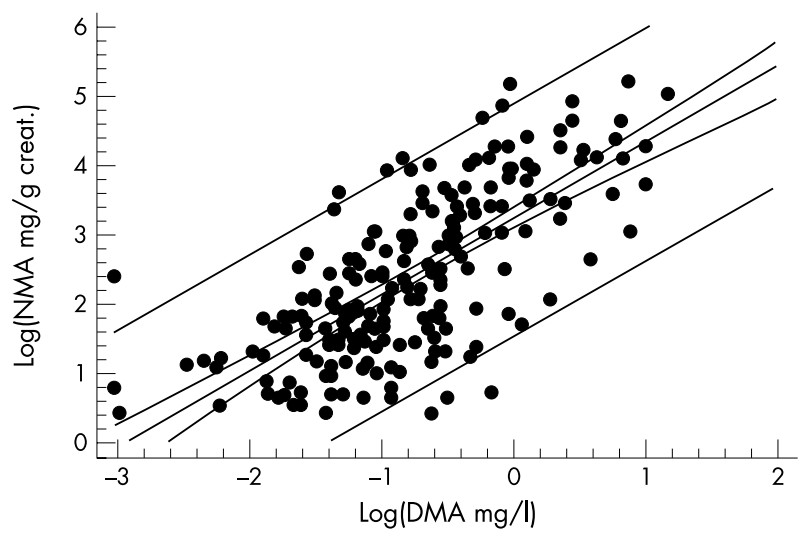

Figure 1 Correlation between urinary NMA and DMA at the end of a shift. $\log (\mathrm{NMA} \mathrm{mg} / \mathrm{g}$ creat.) $=1.099 \log (\mathrm{DMA} \mathrm{mg} / \mathrm{l})+3.16$; $r=0.706 ; \mathrm{n}=223 ; \mathrm{p}<0.001$.

line, after logarithmic conversion. Forty five urine samples had NMA higher than $30 \mathrm{mg} / \mathrm{g}$ creatinine.

Environmental DMA, measured at different times of year, in different parts of the working room, and in all working conditions, consistently gave a rather uniform and very limited exposure for each worker (median value never in excess of 1.5 ppm DMA). The wide distribution of urinary NMA and DMA levels, and their linear correlation, suggest that environmental DMA was not enough to account for the results obtained from the biological samples. NMA levels were high in the urine of workers who had recently started up machinery. Those attending the production control always had urinary NMA lower than $30 \mathrm{mg} / \mathrm{g}$ creatinine.

Table 3 shows results of NMA and DMA urinary concentration obtained in the second stage of the study. Median urinary NMA concentrations at the start of the shift were $4.9 \mathrm{mg} / \mathrm{g}$ creatinine, rising to $5.0 \mathrm{mg} / \mathrm{g}$ creatinine during the shift and $11.6 \mathrm{mg} / \mathrm{g}$ creatinine at the end of the shift. These differences were statistically significant $(p<0.001)$. Comparison of the medians showed significantly different

Table 3 Main statistical parameters for workers exposed in the second phase of the study: urinary NMA (mg/g creat.) and DMA (mg/l), at the beginning of the shift $(\mathrm{n}=35)$, at the end of machine start up (about halfway through the shift, $n=33$ ), and at the end of the shift $(n=35)$

\begin{tabular}{|c|c|c|c|c|c|c|}
\hline \multirow{2}{*}{$\begin{array}{l}\text { Statistical } \\
\text { parameters }\end{array}$} & \multicolumn{3}{|l|}{ NMA } & \multicolumn{3}{|l|}{ DMA } \\
\hline & Start shift & Mid shift & End shift & Start shift & Mid shift & End shift \\
\hline Average & 7.3 & 7.8 & 14.2 & 0.18 & 0.39 & 0.69 \\
\hline Median & 4.9 & 5.0 & 11.6 & 0.16 & 0.41 & 0.69 \\
\hline Minimum & 1.5 & 1.5 & 5.6 & 0.05 & 0.13 & 0.18 \\
\hline Maximum & 30.6 & 26.5 & 44.6 & 0.64 & 0.80 & 1.86 \\
\hline
\end{tabular}

Some urine samples were excluded because of their creatinine concentration (see materials and methods). 


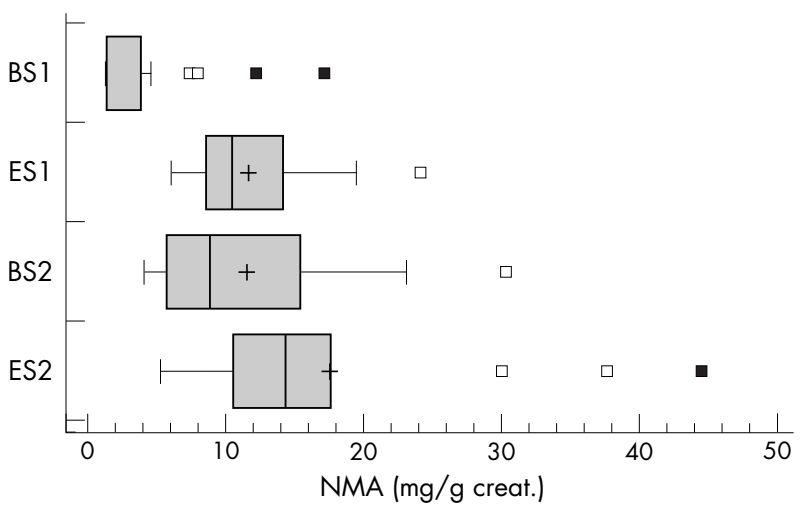

Figure 2 Statistical parameters of urinary $\mathrm{N}$-methylacetamide $(\mathrm{mg} / \mathrm{g}$ creat.) before and at the end of different working days. BS1, before shiff on the 1st working day; BS2, before shift on the following working days (2nd or 3rd); ES1, end of shift on the 1st working day; ES2, end of shift on the following days (2nd or 3rd).

urinary NMA at the start and end of the shift ( $p<0.001)$, as well as during and at the end of the shift $(p<0.001)$. The difference in NMA at the start of the shift and in mid-shift was not significant. For unmodified DMA there is a clear and statistically significant increase in urinary concentration of the solvent throughout the shift (table 3). Median urinary DMA rose significantly from the start of the shift to midshift, and from mid-shift to end-shift $(\mathrm{p}<0.001)$.

The breakdown of data according to the day (fig 2) gave some interesting results. Median urinary NMA before resuming work after two days rest $(2 \mathrm{mg} / \mathrm{g}$ creatinine) was much lower than before resuming work on second or third work shift $(9.8 \mathrm{mg} / \mathrm{g}$ creatinine $)(\mathrm{p}<0.001)$. Similarly, median urinary NMA at the end of the shift on the first day (after rest) was lower ( $10.2 \mathrm{mg} / \mathrm{g}$ creatinine) than on the following days $(14.4 \mathrm{mg} / \mathrm{g}$ creatinine) $(\mathrm{p}<0.001)$.

For unmodified urinary DMA, there was no accumulation during the different days of exposure. Low concentrations in pre-shift urine and increasing concentrations in urine samples collected at the end of the shift showed a typical fluctuating pattern.

Table 4 summarises the statistical parameters for urinary NMA and DMA in relation to use of a mask and immersion of the hands in a DMA solution. End of shift urinary NMA did not differ significantly in the 17 workers who wore active charcoal masks during machine start up and those who did not. This means that respiratory absorption of DMA was not different in the two groups of workers.

Table 4 also shows end of shift urinary NMA and DMA for workers involved in machine start up, some of whom immersed their hands (protected by gloves) in a DMA-water solution. Here again, there was no statistically significant difference in end of shift NMA. This indicates that gloves gave adequate protection.

Table 5 and fig 3 show results of the third stage in the study. Median NMA at the beginning of the first day's work after two days rest is comparable with that found in the second stage of the study ( 1.5 and $2.0 \mathrm{mg} / \mathrm{g}$ creatinine respectively). The statistically significant increase in NMA between the start and end of the shift $(p<0.001)$ is also comparable (see fig 3 ). At the beginning of the second and third workdays, median concentrations ( 3.5 and $4.7 \mathrm{mg} / \mathrm{g}$ creatinine) are significantly higher than on the first day $(p<0.001)$ (table 5). These values are much lower than those found during the second stage of the study $(8.9 \mathrm{mg} / \mathrm{g}$ creatinine) (fig 2).

DMA kinetics rose during exposure, but were always low in pre-shift urine. These data were similar in both the second and third stages of the study (tables 3 and 5).

Taking a shower at the end of the shift work (as planned during the third phase of the study) lowered the urinary NMA in the morning, probably by stopping subsequent absorption of DMA once exposure was over.

Urinary NMA kinetics, calculated from median NMA at the end of the shift and on the following morning, gave values of about 10 hours.

\section{Biotransformation of DMA in humans and} identification of S-acetamidomethyl-mercapturic acid The last part of the results includes data on biotransformation of DMA in humans.

Some urine samples of workers exposed to DMA were used to examine two specific questions. The first was the possibility that NMA and acetamide are present in urine mainly as precursors, decomposing during gas chromatography. The second question concerned further possible forms of biotransformation for DMA.

Figure 4 shows the percentage urinary concentration of NMA and acetamide at gas chromatograph injector temperatures of $150^{\circ}$ and $200^{\circ}, 100 \%$ being the concentration at $250^{\circ} \mathrm{C}$. Differences are very pronounced and statistically significant. Urinary NMA at $150^{\circ} \mathrm{C}$ and $200^{\circ} \mathrm{C}$ is $38 \%$ and $83 \%$ respectively. Acetamide (probably present in urine as Nhydroxymethylacetamide) showed a similar trend (fig 4). The main urinary DMA metabolite is probably $\mathrm{N}$-hydroxymethyl$\mathrm{N}$-methylacetamide, which becomes NMA when injected into the gas chromatograph at $250^{\circ} \mathrm{C}$. This is similar to what happens with $\mathrm{N}, \mathrm{N}$-dimethylformamide, ${ }^{17}$ whose main metabolite, N-hydroxymethyl-N-methylformamide, is transformed into N-methylformamide during the gas chromatographic analysis. Further studies will be necessary

\begin{tabular}{|c|c|c|c|c|}
\hline Statistical parameters & Without mask & With mask & $\begin{array}{l}\text { No immersion of } \\
\text { hands }\end{array}$ & Immersion of hands \\
\hline \multicolumn{5}{|l|}{ NMA (mg/g creat.) } \\
\hline Average & 12.8 & 15.7 & 12.6 & 14.5 \\
\hline Median & 11.9 & 10.7 & 11.7 & 10.4 \\
\hline Minimum & 6.6 & 5.6 & 6.4 & 5.6 \\
\hline \multirow{2}{*}{\multicolumn{5}{|c|}{ DMA (mg/l) }} \\
\hline & & & & \\
\hline Average & 0.77 & 0.61 & 0.66 & 0.75 \\
\hline Median & 0.71 & 0.65 & 0.69 & 0.68 \\
\hline Minimum & 0.22 & 0.18 & 0.18 & 0.26 \\
\hline Maximum & 1.86 & 0.98 & 1.25 & 1.86 \\
\hline
\end{tabular}


Table 5 Main statistical parameters for the third phase of the study: urinary NMA and DMA, from the beginning of the shift on the first day to the beginning of the shift on the third day

\begin{tabular}{|c|c|c|c|c|c|}
\hline \multirow{2}{*}{$\begin{array}{l}\text { Statistical } \\
\text { parameters }\end{array}$} & \multicolumn{2}{|c|}{ First day at work } & \multicolumn{2}{|c|}{ Second day at work } & \multirow{2}{*}{$\begin{array}{l}\text { Third day } \\
\text { Start shift }\end{array}$} \\
\hline & Start shift & End shift & Start shift & End shift & \\
\hline \multicolumn{6}{|c|}{ NMA (mg/g creat.) } \\
\hline Count & 17 & 14 & 13 & 14 & 13 \\
\hline Average & 2.5 & 10.8 & 4.7 & 17.6 & 4.9 \\
\hline Median & 1.5 & 10.0 & 3.5 & 17.2 & 4.7 \\
\hline Minimum & 1.5 & 2.7 & 1.5 & 7.1 & 2.7 \\
\hline Maximum & 10.3 & 21.9 & 11.7 & 28.2 & 7.1 \\
\hline \multicolumn{6}{|l|}{$\mathrm{DMA}$ (mg/l) } \\
\hline Count & 17 & 15 & 17 & 17 & 16 \\
\hline Average & 0.22 & 0.73 & 0.35 & 1.02 & 0.19 \\
\hline Median & 0.20 & 0.61 & 0.34 & 1.06 & 0.17 \\
\hline Minimum & 0.09 & 0.26 & 0.08 & 0.27 & 0.07 \\
\hline Maximum & 0.53 & 1.97 & 0.97 & 2.15 & 0.34 \\
\hline
\end{tabular}

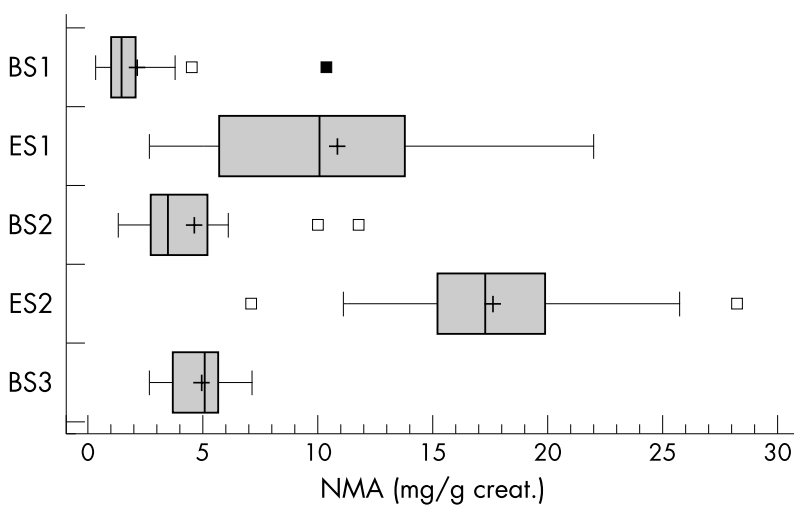

Figure 3 Statistical parameters of $\mathrm{N}$-methylacetamide in urine samples (mg/g creat.) collected during the third stage of the study. BS1, BS2, and BS3, before shift on the 1st, 2nd, and 3rd working day respectively; ES1 and ES2, end of shift on the 1st and 2nd working day respectively.

to confirm this hypothesis, but our results are a good starting point.

Some urine samples were treated as suggested by Ghittori and colleagues, ${ }^{16}$ to measure $\mathrm{N}$-acethyl-S-(N-methylcarbamoyl)-cysteine. The chromatographic peak separated by HPLC was analysed by HPLC with a mass detector and by NMR. The first method indicated a product with a molecular weight of 234 daltons; NMR confirmed the presence of mercapturic acid (see fig 5), with the metabolic pathway of DMA prepared as explained in this paper.

The recent synthesis of S-acetamidomethyl-mercapturic acid has strengthened this initial hypothesis and prepares the

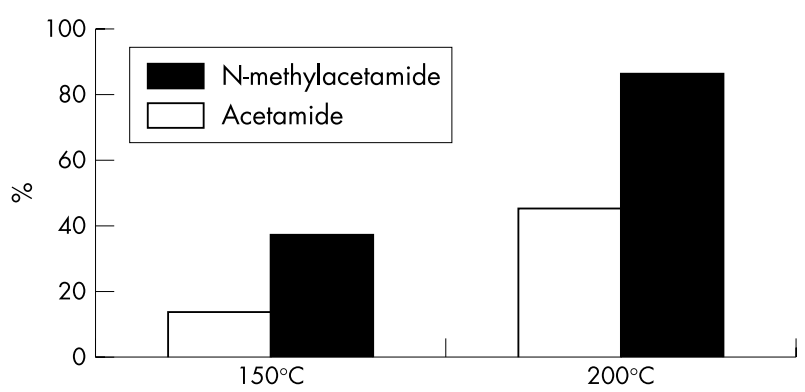

Figure 4 Percentage of $\mathrm{N}$-methylacetamide and acetamide when urine was injected into the GC/MS at different temperatures $\left(150^{\circ}\right.$ and $200^{\circ} \mathrm{C}$ ). The value obtained at $250^{\circ} \mathrm{C}$ is considered to be $100 \%$.<smiles>CC(=O)N(C)CO</smiles>

$\mathbf{N}, \mathbf{N}$-dimethylacetamide $\mathrm{N}$-(hydroxymethyl)- $\mathrm{N}$-methylacetamide<smiles>CC(=O)NCO</smiles>

$\mathrm{N}$-methylacetamide<smiles>CC(=O)NCSCC(NC(C)=O)C(=O)O</smiles>

$\mathrm{N}$-hydroxymethylacetamide

S-acetamidomethyl-L-acetylcysteine (S-acetamidomethyl-mercapturic acid)

Figure 5 Proposed metabolic pathways of $\mathrm{N}, \mathrm{N}$-dimethylacetamide in humans.

way for quantification of this new metabolite of DMA, never previously found in animal or human studies.

\section{DISCUSSION}

\section{$\mathrm{N}, \mathrm{N}$-dimethylacetamide and $\mathrm{N}$-methylacetamide} analysis

The few studies on biological monitoring of professional exposure to NMA are not easily comparable. 
As indicated in the introduction, the reported half life of NMA in urine varies. ${ }^{6}{ }^{10}$ Our data for NMA kinetics are a little higher than those of Nomiyama and colleagues. ${ }^{6}$ In our opinion, these differences are mainly related to the different methods of urine sampling, and perhaps the different forms of absorption (dermal or pulmonary). Our data concern only two phases of urine collection (at the end of the shift and the morning after), while Nomiyama and colleagues ${ }^{6}$ obtained urine samples every 3-6 hours after exposure-the best way of calculating the half life of NMA in urine. If we had used the results obtained during the second phase of the study, the half life of NMA in urine would have been very long (fig 2), close to the results of Borm and colleagues. ${ }^{12}$ The apparent tendency of NMA to accumulate in urine during subsequent workdays was not related to the slow kinetics of NMA in urine. The probable explanation is dermal absorption of DMA, especially outside working hours. In our opinion, the most reliable data on the kinetics of NMA in urine are those of Nomiyama and colleagues. ${ }^{6}$ Our data are consistent with their results.

As shown during the third phase of the study (table 5), a shower and change of clothing at the end of the shift were associated with significant decrease in urinary NMA the morning after. In our opinion, DMA is absorbed by sweat (which acts as a diffusive sampler), passes through the skin, and continues to penetrate the body even after the end of the shift. DMA has a boiling point of $165^{\circ} \mathrm{C}$, and only its removal from the skin prevents its absorption.

During working time, the amount of DMA absorbed (measured by urinary NMA concentration) was similar in the second and third phases of the study. The increase in the metabolite concentration in samples collected before and at the end of the shift was similar, as shown in table 5 and fig 2. The median increase was about $8-14 \mathrm{mg} / \mathrm{g}$ creatinine.

Identification of S-acetamidomethyl-mercapturic acid The identification of a new metabolite of DMA, and data suggesting that NMA is at least in part an artefact of gas chromatographic analysis, prompt some considerations about the toxicity of this solvent. Unlike N,N-dimethylformamide, the synthesis of methylisocianate as an intermediate byproduct during transformation from DMA to S-acetamidomethyl-mercapturic acid is not conceivable (fig 5). The important implication of this statement is that DMA could be less dangerous in humans and animals than $\mathrm{N}, \mathrm{N}-$ dimethylformamide. The toxicological characteristics of DMA are due to its metabolic properties, different from those of N,N-dimethylformamide, which proved more toxic than DMA in some experimental studies. ${ }^{18}$

Further studies will clarify the role of S-acetamidomethylmercapturic acid within the toxicological profile of DMA, and its possible use for monitoring occupational exposure to this solvent.

\section{CONCLUSIONS}

These experiments show that, in some working conditions, environmental DMA may be very low, but absorption of the solvent by workers may nevertheless be considerable.

- DMA can stick to the skin, especially if it is wet (thus acting as a passive sampler). Both during and after work, DMA is continuously absorbed by the skin. A shower and change of clothing at the end of the shift significantly reduce absorption of the solvent.

- Urinary NMA and DMA are useful biomarkers for monitoring professional exposure to DMA. Their urinary kinetics being rather fast, they show recent exposure to the solvent.

- S-acetamidomethyl-mercapturic acid was identified as a new metabolite of DMA, while NMA is mainly derived from $\mathrm{N}$-(hydroxymethyl)- $\mathrm{N}$-methylacetamide during gas chromatographic analysis.

\section{ACKNOWLEDGEMENTS}

We thank Prof. A Fornasa (from the Marzotto Technical Institute, Vicenza) for synthesis of the S-acetamidomethyl-mercapturic acid, and Drs C Marchioro and A Zaramella (Glaxo-SmithKline, Verona) for NMR and HPLC/MS analyses. The authors are grateful to the plant management of Montefibre, Porto Marghera (Venice, Italy) for their support during the investigation, and to Dr P Mead for linguistic revision of the manuscript.

\section{Authors' affiliations}

L Perbellini, A Princivalle, Department of Medicine and Public Health, University of Verona, Italy

M Caivano, Medical Service, Montefibre SpA, Venezia, Italy R Montagnani, Service of Occupational Medicine, Venezia, Italy

\section{REFERENCES}

1 Gescher A, Threadgill MD. N,N-dimethylacetamide. In: Ethel Browning's toxicity and metabolism of industrial solvents. Vol. II: Nitrogen and phosphorus solvents. Elsevier, 1990:143-8.

2 Malley LA, Slone TW Jr, Makovec GT, et al. Chronic toxicity/oncogenicity of dimethylacetamide in rats and mice following inhalation exposure. Fundam Appl Toxicol 1995;28:80-93.

3 Kennedy GL. Biological effects of acetamide, formamide and their monomethyl and dimethyl derivates. Crit Rev Toxicol 1986;17:129-82.

4 Sang-Nam K. Preclinical toxicology and pharmacology of dimethylacetamide, with clinical notes. Drug Metab Rev 1988;19:345-68.

5 Corsi GC. Sulla patologia professionale da dimetilacetammide. Med Lav $1971: 62: 28-9$

6 Nomiyama T, Omae K, Ishizuka C, et al. Dermal absorption of N,Ndimethylacetamide in human volunteers. Int Arch Occup Environ Health 2000;73:121-6.

7 Maxfield ME, Barnes JR, Azar A, et al. Urinary excretion of metabolite following experimental human exposure to DMF or to DMAC. J Occup Med 1975;17:506-11

8 ACGIH, American Conference of Governmental Industrial Hygienists. Threshold limit values for chemical substances and physical agents and biological exposure indices. Cincinnati: AGIH, 2001.

9 DFG, Deutsche Forschungsgemeinschaft (Commission for the investigation of health hazards of chemical compounds in work area). List of MAK and BAT values. Weinheim/Germany: VCH Publishers, 2001.

10 Barnes JR, Ranta KE. The metabolism of dimethylformamide and dimethylacetamide. Toxicol Appl Pharmacol 1972;23:271-6.

11 Kennedy GL Jr, Pruett JW. Biological monitoring for dimethylacetamide: measurements for 4 consecutive weeks in a workplace. J Occup Med 1989;31:47-50.

12 Borm PJA, De Long L, Vliegen A. Environmental and biological monitoring of workers exposed to dimethylacetamide. J Occup Med 1987;29. 898-903.

13 Spies GJ, Rhyne RH, Evans RA, et al. Monitoring acrylic fibre workers for liver toxicity and exposure to dimethylacetamide 1. Assessing exposure to dimethylacetamide by air and biological monitoring. J Occup Environ Med 1995;37:1093-110.

14 Ghittori S, Imbriani M, Pezzagno G, et al. The urinary concentration of solvents as a biological indicator of exposure: proposal for the biological equivalent exposure limit for nine solvents. Am Ind Hyg Assoc J 1987:48:786-90.

15 Threadgill MD, Gledhill AP. Synthesis of peptides containing S-Nalkylcarbamoyl-cysteine residues, metabolites of $\mathrm{N}$-alkylformamides in rodents and in human. J Org Chem 1989;54:2940-9.

16 Ghittori S, Maestri L, Cottica D, et al. Determination of N, acetyl-S-(Nmethylcarbamoil)cysteine (AMCC), a urinary metabolite of $\mathrm{N}, \mathrm{N}$ dimethylformamide (DMF) by high-performance liquid chromatography. 3rd Intern. Scient. Conf. IOHA, Crans Montana, Switzerland, 13-18 September 1997.

17 Kawai T, Yasucgi T, Mizunuma K, et al. Occupational dimethylformamide exposure. 2.Monomethylformamide excretion in urine affer occupational dimethylformamide exposure. Int Arch Occup Environ Health 1992;63:455-60.

18 Stula EF, Krauss WC. Embryotoxicity in rats and rabbits from cutaneous applications of amide-type solvents and substituted ureas. Toxicol Appl Pharmacol 1977;41:35-55. 